\title{
Thinking (with) the Unconscious in Media and Communication Studies: Introduction to the Special Issue
}

\author{
Steffen Krüger ${ }^{1}$ \\ University of Oslo, Norway \\ Jacob Johanssen ${ }^{2}$ \\ University of Westminster, United Kingdom
}

doi: $10.5937 /$ comman 11-13131

Abstract: Under the title Digital Media, Psychoanalysis and the Subject, this special issue of CM: Communication and Media seeks to reassess and reinvigorate psychoanalytic thinking in media and communication studies. We undertake this reassessment with a particular focus on the question of what psychoanalytic concepts, theories as well as modes of inquiry can contribute to the study of digital media. Overlooking the field of media and communication studies, we argue that psychoanalysis offers a reservoir of conceptual and methodological tools that has not been sufficiently tapped. In particular, psychoanalytic perspectives offer a heightened concern and sensibility for the unconscious, i.e. the element in human relating and relatedness that criss-crosses and mars our best laid plans and reasonable predictions. This introduction provides an insight into psychoanalysis as a discipline, indicates the ways in which it has been adopted in media research in general and research into digital media in particular and, ultimately, points to its future potential to contribute to the field. social

Keywords: digital media, the unconscious, psychoanalysis, subjectivity, the psycho-

\footnotetext{
1 Contact with author: Steffen.Krueger@media.uio.no.

2 Contact with author: J.Johanssen@westminster.ac.uk.
} 


\section{Introduction}

For the past two decades, critical research into media and communication has sought ways to understand the significant shift brought about by digitalisation and the proliferation of networked online media. With this shift, questions of individuality, the single media user as an entity and her/his relations to society have taken on a renewed salience. Digital media enable individual choices with regard to how media content is selected, appropriated, (dis)engaged with and modified on an unprecedented scale. Such developments have resulted in scholarship that has explored individual agency and questions of power in relation to digital media in manifold ways, be it through simple consumption choices, online activism, fan practices or many other forms of engagement.

At the same time, the individual as such has become part of the content being produced. People find themselves instigated to express and share who they are and relate to others via multiple, networked media channels on diverse platforms that create - afford, shape and suggest - relations that indicate just how interminable the processes of subjectification and individualisation are. Within the corporate realm, these platforms are characterised by the double objective of enabling feelings of community whilst also profiting from the ensuing communication (see e.g. Burston, Dyer-Witheford \& Hearn, 2010; Fisher, 2012; Fuchs, 2014; Krüger \& Johanssen, 2014; Krüger, 2016). Relying on targeted data extraction as business models (Turow, 2011; Fuchs, 2014), the relations they facilitate tend towards the commodification of the individual and, intentionally or not, open up possibilities for corporate and governmental surveillance. Thus, a focus on "big data" (boyd \& Crawford, 2012), the politics of algorithms (Bucher, 2012; Mager, 2012; Gillespie, 2014), media populism (Moffitt, 2016) and, recently, so-called "fake news" (Bessi \& Ferrara, 2016; Giglietto et al., 2016) have complicated accounts that emphasise individual choice and agency by pointing out how these individual choices become aggregated into the behaviours of "new masses" (Baxmann et al., 2014).

The notions and concepts with which researchers have sought to emphasise and highlight relevant aspects of this shifting situation, such as "convergence" (Jenkins, 2006), "connectivity" (van Dijck, 2013), "participation" (Jenkins, 2006; Carpentier, 2011), "produsage” (Bruns, 2008), "interactivity” (Lister et al., 2009: 21ff), "user-generated content" (Kaplan \& Haenlein, 2010), and "digital labour" (Terranova, 2000; Fuchs, 2014) have long since become com- 
mon parlance. They are challenged and defended, changed and rearranged. A variety of approaches, theories, models and assumptions attach themselves to these concepts that focus on a diverse range of angles, including gender, ethnicity, class, subculture and group memberships from micro, meso and macro perspectives. With these come diverse philosophies and worldviews that often concern questions of activity, passivity and agency with regard to media use as well as media power.

Yet, whereas many of these approaches can be seen as responses to the renewed interest in, as well as centrality of, the individual media user, the conceptions of the subject and subjectivity underlying these works frequently remain implicit and in need of reflection and clarification. What is established by such "implicit notions" of subjectivity (Dahlgren, 2013: 72) is an idea of media users leaning strongly towards rationality, cognition, categorisation and assimilation. While, as mentioned above, consumer choices become ever finer grained to meet individual demand and while content is frequently tailored to meet the expectations, or suspicions, of political loyalists, the challenge that the resulting notions of individuality pose to our conceptions of the subject have only started to be confronted by media and communication research and related fields (see Wilson, 2010; Lupton, 2016; Bröckling, 2016).

In order to counter the tendency of foregoing the relevance of subjective experience and its impact on the social, Peter Dahlgren has recently advocated "reactivating concerns about the subject" (2013: 73) in media studies research, stating that researchers in the field also need to consider "communicative modes beyond the rational" (2013: 82). Heeding this call, psychoanalysis may be one, if not the discipline, best equipped to point to ways out of the rationalistic impasse. As Brown and Lunt suggest, "there is something about psychoanalysis that is corrosive to the whole model of the subject built up by the social identity tradition" (2002: 8) - i.e. the very tradition to which implicit models of the subject in media and communication studies frequently default.

This special issue understands itself as a critical appreciation of this "corrosiveness" of psychoanalytic theory as a productive potential for media and communication studies. With its diverse traditions - Freudian, Kleinian, Lacanian, Winnicottian, relational, etc. - foregrounding the conflicted, ambivalent, defended, divided, desirous, wishful, multifaceted, layered and processual aspects of human beings in their relations with others, psychoanalysis shifts our 
attention to contradiction, incoherence, ambiguity, resistance and enjoyment in media texts and mediums as well as in our responses to them.

While psychoanalysis is primarily a clinical field, the application of theoretical and methodological concepts outside the consulting room has shown that they can be immensely fruitful and productive if the specificity of the social context in which they are used is kept in view. Thus, instead of colonising the social with the psychical, which was one of the cardinal mistakes of early psychoanalytic research, the focus is now firmly on the kinds of connections between the psychic and the social, the co-constitution of the psychic and the social and/or their mutual implication in one another (Hollway \& Jefferson, 2000; Frosh, 2012).

As regards the in-depth study of this co-constitution, or mutual implication, of the psychic and the social, the media, media technologies and the user's relationship to these play a key role. In Western societies at the onset of the 21 st century, questions regarding socialisation, individualisation and subjectivation can only thoroughly and satisfactorily be answered when we take our relations in, through and with media into consideration. In this respect, what is most striking from a psychoanalytic (but also from other, e.g. post-human and new materialist) perspective(s), is the movement of information and communication technology ever closer to the human body and into each and every aspect of everyday life. With the steady increase in computing power and a significant rise in wireless transmission rates, with devices becoming smaller, lighter, more mobile and ever more able to merge with the human body, a media sphere has developed that is rapidly becoming a major, integral influence on the ways in which we relate to and interact with others - ways that psychoanalysis holds to be vital for subjective development.

While the articles collected in this issue of $C M$ each inquire into specific scenarios of and challenges resulting from this proximity and integrality, what follows is a more general inquiry into the relationship between the psychoanalytic unconscious and the current media situation. This assessment is followed by the introduction of the articles collected in this issue in the context of existing currents of psychoanalytically oriented research on digital media. We end the introduction with an outlook on the future of psychoanalytic media research. 


\section{Digital Media and the Psychoanalytic Unconscious}

As briefly broached above, psychoanalysis is, first of all, a clinical method of treating mental illnesses that arise from intra- and intersubjective dynamics. Advances in psychoanalytic theory have always been closely tied to what would emerge from the interactions between analysand and analyst in the consulting room. From the very beginning, however, this mode of theory production became fertilised by analysts drawing on cultural materials and artefacts. When, in the decisive phase of the foundation of psychoanalysis, Freud reported to his friend, Wilhelm Fliess, that he had found in himself a strong love for his mother and jealousy towards his father, he immediately referred this finding to the "gripping power of Oedipus Rex" (Freud, 1962: 193), the antique stage drama by Sophocles (ca. 429-425 BC). Thereby, he connected a psychic insight with a literary character and, as Alfred Lorenzer (1986: 20) further pointed out, "implicitly equate[d] an unconscious experience with the impact of a literary work". In this way, then, cultural artefacts penetrated psychoanalytic theory and practice and, consequently, it did not take long before psychoanalysis started to venture into the realm of culture in return, with the founding of Imago, the "journal for the application of psychoanalysis in the human sciences", in 1912, giving these ventures a platform of their own. Subsequently, the psychoanalytic idiom began to sink into Western thinking, with people interpreting their own, as well as other's, behaviour in terms of repression, resistance, "Freudian slips" etc. Therefore, when we, in this special issue, aim at an assessment and reassessment of digital media from a psychoanalytic perspective, we position ourselves in the tradition of "psychoanalytic explorations" (Kris, 1952) in culture. However, due to the very penetration of psychoanalysis and its terminology into everyday life, this assessment must be done with a keen eye for the original theoretical formulations, the nuanced clinical uses of certain terms and the ongoing debates around them. ${ }^{3}$

Additionally, this self-reflexive turn is suggested by research on psychoanalytic concepts itself. As Drew Westen (1999) wrote in his overview of the scientific status of psychoanalytic concepts, "the most fundamental assumption of psychoanalytic theory and practice is no longer a matter of scientific debate.

Furthermore, as Eli Zaretsky (2015) and others (e.g. Halpern, 2014) have pointed out, psychoanalysis is also in need of self-reflection since its paradigm has increasingly become intermixed with and contested by that of cybernetics. In other words, as our conceptions of subjectivity in its various contexts are in flux themselves, an assessment of digital media - a realm largely driven by cybernetic thinking - from a psychoanalytic perspective also needs to consider the implications of digital culture for psychoanalysis. 
[...] The clear experimental documentation of unconscious thought, feeling, and motivation supports many aspects of psychoanalytic theory and practice" (1999: 1063). Having thus secured a scientific grounding for psychoanalysis, Westen continues his overview by listing various kinds of unconscious processes that the experimental literature has identified. While many of them fall inside the traditional psychoanalytic field of interest, some of them serve functions that diverge from those on which psychoanalysis has focused (Westen, 1999: 1063-1064). Westen therefore suggests a mutual opening of disciplines, so that academic disciplines become receptive of psychoanalytic insight, but also, vice versa, that psychoanalysis take on board the implications derived from findings made in other fields.

For the purposes of the present article, while we cannot follow Westen's appeal systematically, what we would like to take with us into our outline of psychoanalytic thinking in digital media studies are the following two points: While it is necessary (A) to think the unconscious and to think with the unconscious in media and communication studies, it is just as necessary to (B) approach and use traditional psychoanalytical terminology as a heuristic device and in a way that is committed, but never uncritically bound to this terminology. Thus, as indicated above, we want to conceive of the concepts and elements of psychoanalysis as open and malleable to the demands and implications of the field of digital media. In this spirit, we will now first give an outline of the psychoanalytic unconscious in order to then bring it in touch with the study of digital, online media.

\subsection{The Psychoanalytic Unconscious}

Without doubt, the most central aspect of psychoanalysis is the psychical conflict upon which the unconscious as well as the whole of psychoanalytic theory is based. In his definition, Stephen Frosh points out that the psychoanalytic unconscious

"refers to the existence of ideas which are not just not being thought about (hence not just 'not in consciousness') but which are also radically unavailable to thought - they cannot be brought to awareness even if the person tries really hard, or at least it is more of a struggle than one person can manage on her or his own. These hidden ideas, however, have a profound influence on psychological life." (Frosh, 2002: 12-13) 
Whereas experimental evidence refers us to the existence of various kinds of unconscious processes that are unconscious simply because they are not thought about but are otherwise unproblematically available to consciousness, the specificity of the psychoanalytic unconscious is that it cannot simply be activated and drawn into conscious, rational thinking. Instead, it is actively kept away from consciousness, because its contents are too toxic for the individual and too painful to bear and engage with.

At the same time, unconscious ideas by no means disappear or become entirely forgotten. Rather, as Frosh writes, although they are "hidden from awareness", they still remain "active ('dynamic'), pushing for release" (2002: 13). The process of repression, which becomes constitutive for the psychoanalytic unconscious, has to be an ongoing, continuous one. Not only must intolerable ideas be withdrawn from consciousness, they also have to be kept away from it "by continuing pressure" (2002: 15). As with a taboo that ties prohibition and attraction together in a tense relationship, the forbidden and forbidding nature of unconscious ideas exerts a strong attraction and it is the dialectical, conflictual relation between the desirable and the intolerable in one and the same idea that is constitutive of the psychoanalytic unconscious.

In his second topography, Freud captured the tense dynamic between desire and prohibition in a tripartite structure, namely, between the $I d$, i.e. the drives and their representations, and the Superego, i.e. the conscience function, with the Ego attempting to negotiate and strike a balance between the two with a view to remaining adapted to the demands of (social) reality. As the conflictual nature of the relationship between these three agencies suggests, the qualities and quantities by which adaptedness might be measured are open to negotiation and change. On the intrapsychical plane, these changes occur because we are neither always able to put in the effort that it takes to keep the unconscious in check nor always willing to do so - e.g. because we are mentally exhausted, under stress, in an overwhelming life situation, drunk or otherwise intoxicated, or simply, asleep. In these situations, the repressed unconscious can easily return to us and announce its existence in an abundance of ways, e.g. in dreams, parapraxes (characteristically called "Freudian slips") and in faulty, or even bizarre acts that, in social situations, create scenes about which we later might simply shake our heads. The frequently heard excuse of "I don't know what came over me", or "I wasn't myself in that moment" are typical ways of dissociating from the breaking through of aspects or traits that one might have been attempting to disown. 
It is when looking back on embarrassing situations, such as those implied above, that we might obtain an insight into the existence of an afterlife of infantile thinking and acting - an afterlife that is part of the unconscious, since many of those ideas and scenes that we experience as so intolerable that they have to be repressed either stem from, or follow relational patterns, the foundations of which were laid in early childhood. As grown-ups, while we never encounter our unconscious - i.e. that which intolerably, unbearably belongs to us - in a completely unfiltered, undiminished way, our confrontations with it are of varied intensity. As Frosh writes,

"there is, for example, sufficient censorship remaining in dreams to mean that little damage is usually done by them. But sometimes a crisis occurs, for example when the only way in which a tumultuous energy of unconscious life can be contained is to allow some of it expression in the form of neurotic symptoms." (2002: 23)

Similar to dreams, such symptomatic expressions function as openings into a person's unconscious. However, it is important not to understand them as pure and straightforward expressions of it; what is breaking through in symptoms is not a voice speaking directly from the "depths" of the unconscious. Rather, symptoms can be understood as compromise formations that organise and regulate psychic life by creating provisional outlets. The unconscious manifests itself, then, in expressions that are riddled with metaphors and metonymies, as well as the Ego's defensive attempts at keeping these expressions within the conventions of the normal. Anna Freud (1936/1984), in particular, devoted a significant part of her theoretical work to identifying and differentiating these defence mechanisms and naming them according to their functions, e.g. projection, identification, rationalisation etc. But other traditions, first and foremost that based on the works of Melanie Klein, have also identified mechanisms that have immense value for understanding psychic dynamics, such as splitting and projective identification (see e.g. Hinshelwood, 1991).

Due to these theoretical developments, the concept of repression is now being used in two different ways. On the one hand - and in its more general usage - it has become an umbrella term for the various mechanisms with which people attempt to fend off the anxiety that announces the breaking-through of the unconscious. After all, as Frosh (2002) states, "once the workings of repression are fully described, it becomes apparent that all defences have a similar func- 
tion, which is to keep unconscious impulses at bay. So, every defence involves repression, and repression in the general language sense is what every defence does." (Frosh, 2002: 21) On the other hand - and in its more specific usage repression becomes one defence mechanism amongst others, with all of them serving the Ego to retain homeostasis and a relatively workable and endurable mode of functioning. Yet, they achieve this in a way that is not completely harmless. The more established the defences against the threatening "return of the repressed" (Freud, 1915) become, the more the subject becomes caught up in the anxious abating of its conflicts, in a precarious, highly inhibiting management of unthinkable desires and life threatening prohibitions.

The clinical process of psychoanalysis is geared towards the analysand, in small steps taken in dialogue with the analyst, developing an awareness of exactly those patterns of thinking, feeling, relating to and interacting with others that continuously re-enact and reproduce the conflicts upon which his/her unconscious and its ensuing dynamics thrive. The ultimate aim is to make these patterns lose their efficacy and binding power. However, since the unconscious is a dynamic of thinking that is principally outside language, with unconscious ideas behaving more like things than words, and since psychoanalysis is a process in which language and speech are central for the acknowledgement of inner states, the unconscious can never be wholly captured, understood and explained in and through its efforts. Furthermore, analysands can never be completely 'healed' of the symptoms from which they suffer, nor should we hope for such a healing. After all, since it is also our unconscious that makes us who we are, a complete recovery would also mean a total change of personality.

Summarising our account so far: What distinguishes psychoanalytic from other kinds of unconscious processes is its dynamism - a dynamism that is based on a tense, conflicted relation between various psychic agencies, in the classic Freudian conception between the It, the Superego and the Ego, which might be translated as desire, duty and reality. The psychoanalytic unconscious is not so much a realm or place, but rather, should be conceived of as a process in which intolerable ideas and imaginations become withdrawn from consciousness. Becoming repressed, these imaginations then become constitutive of the unconscious, (a) because they need to be kept from becoming conscious on a continuous basis. And since this is not always possible or even desirable, unconscious ideas (b) make their presence known as symptoms that emerge in 
different situations, ways and intensities. In this way, writes Frosh, unconscious ideas are also causal - they make us who we are and produce "much of the weft and warp of psychic life, its richness and its confusion" (Frosh, 2002: 13-15).

\subsection{Thinking (with) the Unconscious in Digital Media}

Arguably, continuing from the above, it is by no means obvious how the psychoanalytic unconscious in its dynamic complexity can be brought into play in the study of media content and form. That which is brought to the fore in clinical psychoanalysis, in the relation between analyst and analysand, seems to entail far too personal and intimate a knowledge as to pertain to the study of institutional and sociocultural practices. Since the psychoanalytic unconscious is constituted by that which is too painful for the individual to associate with and through the very act of keeping these thoughts, imaginations and experiences away from consciousness and from expression in the social, how could they ever have an impact upon the sociocultural at all? By the same token, however, the above question can also be turned on its head. Since our unconscious plays a vital part in who and what we are, not only in symptomatic expressions, but also by pushing our personal development into directions that emerge from the necessity to respond to and manage our conflicted and conflictual needs, it is indeed highly improbable that this unconscious, as it is shaped by the social, does not also play a vital role in shaping the social in return.

Questions regarding the exact relationship between the psychic and the social have been vexing researchers throughout the 20th century. Since the early attempts of the Frankfurt School, critical theorists have sought to combine sociological accounts of the workings of the social with psychoanalytic accounts of the workings of the human psyche. However, while straightforward attempts at coordinating these two poles have hardly ever been convincing - e.g. Herbert Marcuse's terms, such as "surplus-repression" (Marcuse, 1955), suggest to us somewhat too clear-cut equivalences - recent times have seen some far more sophisticated advances in mediating between the psychic and the social and we will touch upon them in our overview of the traditions of psychoanalytic thinking within media and communication below.

However, a limitation of many of these approaches is that their focus is very much on media content and its potential effects - a focus that comes at the expense of the media's forms of mediation themselves. In view of the ubiquity of digital media, shifting our attention to the specific ways of mediation and 
their impact becomes increasingly important. With media technologies becoming ever more mobile and moving ever closer to the body as well as into things (which are thus turned into non-human actors), our interest in unconscious processes needs to be opened out to the question of how far and in what ways do these media themselves come to play a part in their audiences' subjectivities and, vice versa, how far and in what ways do audiences themselves come to play a part in the media's agency. Therefore, as the next step in this subchapter, we want to turn to the question of how we might describe a process of media socialisation (or even subjectivation) from the point of psychoanalytic theory.

\subsection{1. "Online Disinhibition" - An Exemplary Case of Understanding the Digital Psychoanalytically}

One scenario in which a process of 'media subjectivation' can be unfolded is offered by John Suler's now classic article on the "Online Disinhibition Effect" (2004). Suler presents six characteristic factors that shape the behaviour of users engaged in communicative practices facilitated by online environments. While some of these factors (they are: "anonymity", "invisibility", "asynchronicity", "solipsistic introjection", "dissociative imagination" and "minimisation of authority") are more promptly understandable than others, Suler's main drift is that all of them must be seen in relation to the loosening of ties with significant others in online interactions - a socio-technological tendency that Sherry Turkle unfolded in her seminal Alone Together (2011) and in subsequent publications (2015). In the scenarios that Suler describes, people act and interact without being burdened by the weight of their social identity and reputation and/or with significantly less consideration for tact and the emotional wellbeing of others. As Suler observes, these situations, although typical of specific online contexts, are also reminiscent of other social situations, particularly that of the psychoanalytic hour itself, to which Suler refers explicitly. Apropos the factor of "invisibility" he writes:

"According to traditional psychoanalytic theory, the analyst sits behind the patient in order to remain a physically ambiguous figure, revealing no body language or facial expression, so that the patient has free range to discuss whatever he or she wants without feeling inhibited by how the analyst is physically reacting." (Suler, 2004: 322) 
Suler holds that in many online environments, too, the absence of bodily signs in response to a user's actions allows this user to push his/her actions ever more into the direction of his/her prior dispositions and proclivities. Furthermore, when he claims that "people say and do things in cyberspace that they wouldn't ordinarily say and do in the face-to-face world", that "they loosen up, feel less restrained, and express themselves more openly" (2004: 321), this shows interesting correspondences with the most basic requirement in psychoanalysis, namely, that the analysand freely associate and give expression to whatever comes to mind (Freud, 1978).

We could continue our playful comparison of Suler's conception of online disinhibition with the psychoanalytic situation here. However, if we take seriously the correspondences between the two situations, then, the more interesting question to consider is what these correspondences imply for the psychoanalytic conception of the subject in these contexts of online disinhibition. Thus, when we take disinhibition to mean the loosening of repression and the emergence of freely associative modes of interaction, must we not expect to find a kind of subjectivity facilitated in these online environments that externalises its unconscious to a far greater extent than psychoanalytic theory could foresee? And, consequently, must we not expect to be confronted there with displays of the unconscious in a decisively rawer form than the concept of repression suggests?

Answering these questions for the specific cases of online disinhibition, it is worth returning to the differentiation between the two uses of the term repression. As stated above, whereas its narrower use points to the specific defence mechanism of repression by which an idea is withdrawn and kept away from consciousness, its more general use points to repression as an umbrella term for various kinds of mechanisms by which unconscious ideas are kept from an individual's awareness. With a view to incidences of online disinhibition, then, repression in the general sense can no longer be seen as performed by repression in the specific sense. Rather, Suler's text suggests that more regressive $e^{4}$ forms of interaction will become commonplace, with less restrained and, indeed, less inhibiting defence mechanisms coming to the fore, e.g. projection, acting out, splitting, idealisation etc.

\footnotetext{
4 We use "regressive" here in its non-pejorative, psychoanalytic sense of a return to less structured and differentiated modes of expression and interaction (see Laplanche \& Pontalis, 1973: 436).
} 
These changes at the interactional level have implications for our overall conception of subjectivity in these contexts, too. After all, if people change the ways in which they cope with anxiety, conflict and desire, this will have consequences for their whole way of being. Thus, in an attempt to capture the potential impact of online disinhibition on subjectivity, it becomes clear from our perspective that online subjectivity is now frequently less guarded and, as a consequence, more vulnerable to fragmentation, with the means to defend against such vulnerability having become more archaic and loud.

Yet, as regards this potential impact on subjectivity, we have to be careful not to colonise all online environments with the above theoretical speculations. Suggesting a vastly sceptical outlook on culture, the online disinhibition effect, as Suler conceives of it, finds an echo in Freud's bleak societal diagnosis in Civilization and its Discontents (1981) and its main thesis that natural human proclivities must be bound by a repressive culture so as to make coexistence at all possible. Along these lines, the introduction of the Internet in general would have to be seen as a dangerous step in a development leading to the loosening of repression on a global scale and to a general re-aggressivisation and re-sexualisation of social ties. To use this conception indiscriminately for all online practices and all relational cultures emerging from them would be a grave mistake.

Rather, while the phenomenon of online disinhibition finds most resonance in social media, online discussion forums and news boards, it seems just as possible to identify practices and environments with markedly different structures of feeling and with cultures in which users' relations to their media call for different theoretical reflections - as well as inflections. The vast field of fandoms and online fan cultures (e.g. Saito, 2011), for example, suggests cooperative and mutually supportive relationships in which ties to significant others are all but loosened and where different kinds of sexualities and, ultimately, subjectivities are being imagined and performed that have the potential to challenge set psychoanalytic expectations in ways that are different from the above.

In turn, when it comes to the field of corporate social networking sites, we can see that they afford forms of interaction that are disinhibiting and highly inhibiting at the same time. While the corporate desire for user-generated content brings forth ever new possibilities for the users to, in Suler's words, "loosen up [...] and express themselves more openly" (2004: 321), this drive towards freely-associative material is countered and contradicted by the desire to attach these associations to the users' true identities (Hogan, 2013). What is being 
suggested in this conflicted mixture of affordances is a form of subjectivity that comes with a strong orientation towards self-marketing and self-commodification and can well be seen as the fulfilment of what Adorno, with a view to the cultural industry, termed "psychoanalysis in reverse" (1954: 223). However, whether or not users comply with this mode of self-fashioning and subjectivation is another matter. Clearly, a significant number of them are keenly aware of the corporate modes of surveillance in place on the sites. And while many users feel either increasingly inhibited to share information there (Marwick \& boyd, 2011, 2014; Stutzman, Gross \& Acquisti, 2012), or use ironic modes of compliance, there is also a proud tradition of subverting, or even sabotaging, the corporate interest in user creativity (e.g. Saco, 2002; boyd, 2014; Karppi, 2015; Phillips, 2015; Krüger, 2016). This tradition again holds potential for identification and subjectivation and goes to show that even those mechanisms that, at the relational level, have a defensive function, might have a sublimating, "progressive" effect at the sociocultural level.

Now, turning to the next subchapter of this introductory article, we will present this issue's contributions in the context of the broader currents of psychoanalytic media research from which they derive.

\section{Mapping Psychoanalytic Research into Media and Communication}

While it is safe to say that psychoanalysis leads a niche existence within most media and communication departments across the world today, with the authors discussed in this section representing a minority in the field, it is nevertheless possible to point to genealogies, or tentative lineages, of psychoanalytic media research. However, the following presentation of these lineages has been made for the sake of summary rather than to canonise authors into set traditions.

\subsection{Critical Theory, Cultural Studies and Psychoanalysis}

As briefly touched upon above, some of the first attempts to combine psychoanalytic and sociological thinking can be traced back to members of the Frankfurt School who sought to combine readings of Marx with Freud in order to critique capitalism and its inherent modes of domination, commodification

\footnotetext{
Marcuse (1964/1991) points in a similar direction with his concept of "repressive desublimation". Also, in this respect, Žižek's critical reading of "cyberspace" as "the suspension of the master" (1997: 193ff) is still very current.
} 
and exploitation, which they came to see as both grounded in structural forces as well as entangled in subjective processes (e.g. Fromm, 1941/1994); Marcuse, 1955; Horkheimer \& Adorno, 1972; Adorno, 1975). All of them touched upon the media in their works to an extent. Perhaps it was Horkheimer and Adorno's chapter on the culture industry, in The Dialectic of Enlightenment (1972), that most famously conceptualised mass media as a form of affirmative pleasure - a pleasure that not only reproduced capitalism's relations of production but was also able to manipulate and shape audiences' tastes and desires. Horkheimer and Adorno's account of the media was received rather sceptically in Anglo-American academic circles where they were accused of conceptualising audiences as too uncritical, passive and pacified. It was British cultural studies in particular that argued for empirical investigations into audiences and how they made sense of the media. In the process, however, the discipline started to lose sight of and turned away from psychoanalysis (Hall, 1980; Morley, 1986; Grossberg, 1987; Couldry, 2000).

By contrast, in post-war Germany, the link between critical theory and psychoanalysis was revitalised by the second generation of the Frankfurt School. Major impulses came from the works of Alexander and Margarete Mitscherlich (1967/2007), the early Habermas (1972) and Alfred Lorenzer (e.g. 1970a, b). The latter in particular, through his works on depth-hermeneutics, offered a viable theoretical and methodological approach to cultural research from a psychoanalytic perspective that still exerts a strong influence on social and cultural research in Germany (see, e.g., König, 2006; Löchel, 2002). From a pragmatic, historical-materialist orientation, depth-hermeneutics conceives of the psychoanalytic concepts of the conscious and unconscious in terms of evolving forms of interaction that are either granted or not granted access to language and conscious modes of thinking. Since these forms evolve from earliest childhood, in repeated interactions between infant and caregiver, the social comes into the picture from the very beginning. As the caregiver is always already a social being, the interactional patterns that take shape in the infant through its encounters with her/him inevitably come to carry a psychic as well as a social dimension.

Vera King's article on the "Transformations of Shame in Digitalized Relationships" is rooted in this tradition. Based on open, unstructured interviews with mobile media users, her analysis captures the sociocultural implications 
of the evolving media practices in dialogue with psychoanalytic and sociological theories of shame. What she finds in her article are "changes in the quality of relationships to physically present - yet communicatively absent - others" (p. 72). Specifically, the absence of shame from situations in which people use digital media while others are physically present points to a shift in relational practices on a sociocultural scale.

\subsection{Feminist Media Studies}

A number of feminist thinkers have and continue to engage with psychoanalytic ideas (Mulvey, 1975; de Lauretis, 1984; Doane, 1987; Copjec, 1989; Cowie, 1990; Silverman 1992). This tradition has primarily been connected to the medium of film and has often drawn on Lacanian theory to describe the ideological (unconscious) effects of cinema on spectators. Lacan posits that our first encounters with ourselves and others are pre-symbolic and of a visual nature. The baby sees herself in a mirror and mirrored through others' reactions towards her and, as a result, mis-perceives herself as a coherent, unified and rational being. The very act of perceiving the self as self is marked by a fundamental break between the I who perceives itself and the self that is perceived as an other. This relationship between the individual and his/her (imagined) other lies at the heart of Lacan's thinking. Laura Mulvey (1975), in turn, adapted Lacan's notion of the mirror stage and coupled it with his theory of the gaze. In her work on Hollywood cinema, she argued that cinema, in its ideological function to reproduce patriarchy, invariably presents female bodies from the perspective of the gaze of the film's male protagonist, so that the audience will unconsciously identify with this gaze and become interpellated by it.

Another tradition of media analysis that has become revitalised over the past decades and which builds strongly on Lacanian psychoanalysis is a version of discourse analysis. For this tradition Lacan's conceptualisations of the symbolic and of discourse are crucial. In his reinterpretation of Freud's unconscious as outside language, Lacan holds that the unconscious is actually a (side)product of our entry into language and the symbolic. Specifically, he ventures that from our first attempts at symbolising experience and desire, and articulating (signifying) these in language, there is something that must become excluded and remain unsaid. In fact, that which remains unsaid only comes into existence as the unsaid through our attempts at articulating 'it' as part of a signifying chain 
in the first place. This unsaid - i.e. that which eludes symbolisation and only comes about through symbolisation - is the unconscious - an unconscious that, enigmatically, is outside and, at the same time, inside language.

The basic dependency of the Lacanian unconscious on language and the symbolic suggests a mode of analysing unconscious aspects in texts without necessarily relating these aspects to individual life-histories. Rather, each linguistic statement in its particular sociocultural context is seen here to evoke a realm of that which cannot be said, which comes to hover over a given scene, and it is this realm that Lacanian discourse analysis is geared to shed light upon. Ian Parker, the main proponent of this research direction, explicitly suggests "ready-made" media texts (Parker, 2010: 157) as a fertile material for this approach. In this way, one can say, the Lacanian analysis of media discourse manages to bypass the narrower biographical dimensions of the psychoanalytic unconscious by focusing on the more general workings of the symbolic. Arguably, this makes this approach less prone to speculations at the level of intimate, personal meanings. At the same time, however, its predominantly social interest makes it debatable as to whether its object of analysis still falls within the realm of the stricter psychoanalytic definition of the repressed unconscious.

Alison Horbury can be seen as being affiliated with this tradition. Her analysis of feminist discourses online is based on Lacan's (2007) conception of the four discourses and their structures. In her article, "Digital Feminisms and the Split Subject", she argues that digital feminist discourse most often takes the form of "the discourse of the hysteric" - a discourse that is inevitably directed towards the Other as "master". As Horbury shows, while this is a necessary discursive position, it also gets stuck in the power relations it seeks to attack. Since the Other is addressed as both the oppressor, but also, unconsciously, as the authority that is to acknowledge the struggle of the hysteric (for example in discourses touching upon patriarchy, toxic masculinity, or anti-feminism), this discourse conserves what it seeks to do away with. Moreover, the more established a given feminist position becomes, the more one can observe a shift in online discussions: the "discourse of the hysteric" becomes replaced by the "discourse of the university". Consecutively, the rhetoric of power shifts from the oppressed protesting against her oppression to a voice claiming authority through knowledge. However, this shift leads to further rifts in and between feminist groups. Since the knowledge that is granted authority is knowledge 
about oppression, hysteric positions now emerge in response to this new feminist authority and in contestation over what kind of feminism shall be given a privileged epistemological position.

\subsection{Queer Theory and Intersectional Studies}

The fields of queer theory and intersectionality studies have also drawn on psychoanalysis when theorising the (queer) body. While there has been resistance to and critique of psychoanalysis, several scholars have made use of psychoanalytic concepts (e.g. Butler, 1990; Dean, 2000; Edelman, 2004; Watson, 2009; Ahmed, 2014). However, not many publications have specifically addressed the media through the prism of queer theory and psychoanalysis. An exception seems to be the evolving field of porn studies, which has shown a tendency to take psychoanalytic concepts into account, as various articles in the recently launched journal of the same title attest (Neville, 2015; Ryberg, 2015; Varghese, 2016).

In a way, Diego Semerene's article criss-crosses the field of queer, porn and media studies. Drawing ethnographically on sexual encounters in group settings, Semerene states that the "digitally assisted gangbang" (through hookup apps and websites) emerges at a particular point in time in which the male body is increasingly made visible online. This constant demand of digital representation puts this body at risk of phallic failure. The gangbang may be read as a cultural symptom where men unite in order to ward off this risk of fragility and (symbolic) impotence through engaging in sexual practices that put an other - primarily women as the gangbanged subjects - in the place of utter inferiority and victimhood. Ultimately, Semerene links these practices to the Freudian narrative of the "great misdeed" (Freud, 1981). Freud saw the initial act of civilisation in the primal horde killing the archfather - a collective act that initiated the sense of kinship among the group members and contained feelings of guilt. By inserting herself into the constellation of the gangbang as a $t$ [rans]girl, Semenere manages to subvert the phallocentrism of this descendant of the "great misdeed" and its socialising dynamics. With the victim's gender rendered ambiguous, the homoerotic and homosocial implications of the act come to the fore. By the same token, the t-girl becomes legitimated as female in this archaic act by being referred to as "she" or "her" by the male collective. Through the insertion of the t-girl, then, the gangbang is shown to effectively destabilise a 
system of binary gendered bodies. Facilitated through digital media, it opens up a space for acts that disrupt the idea that the body is individual, rational and privately owned.

\subsection{Studies of Networked and Mobile Media}

Studies into mobile media (Elliott \& Urry, 2010), gadgets (Krzych, 2010), as well as social media and subjectivity (Flisfeder, 2015; Zajc, 2015) have also shown an interest in psychoanalytic concepts. Again, many of these have drawn on the works of Jacques Lacan (often via the writings of Slavoj Žižek) in order to theorise Internet technology and the use of social media in general, as well as smartphones and applications in particular (Flisfeder \& Willis, 2014). In her influential work on informational or communicative capitalism, Jodi Dean $(2009,2010)$ argues against the widely held belief that social media have contributed to more open and participatory forms of communication. Following Žižek, Dean holds that in contemporary online culture, symbolic efficiency, i.e. the Lacanian (1977) notion of the Symbolic Order, has been diminished. Instead, digital culture is characterised by circuits of the drive. According to Lacan, a drive does not pursue a specific goal, but rather follows an aim as a means in itself, circling around an object without ever capturing it. Communicative capitalism is being kept operative online through drive loops. Users are captured in networks of enjoyment, surveillance and production that do not satisfy a particular desire but merely capture and reproduce drive. "I enter. I click. I like. I poke. Drive circulates, round and round, producing satisfaction even as it misses its aim, even as it emerges in the plastic network of the decline of symbolic efficiency" (Dean, 2010: 60).

Christopher Gutierrez's article, "The Other Self in Free Fall: Anxiety and Automated Tracking Applications", in which he develops the Lacanian notions of affect and anxiety with regard to self-tracking applications, can be seen as a contribution to and continuation of Dean's work. In particular, he considers "self-tracking applications [to] represent a particular affective loop [...] which drives a never-ending anxious attempt" (p. 111) to reunite the subject with itself. As Gutierrez points out, however, anxiety does not emerge from a self as object that is lacking or missing, but from the shock of finding an object where there should not be one. In the case of digital tracking applications, while the subject expects to encounter a gap between itself and its data, the tracking apps constantly seek to close this gap. The embodied self and digital self are conflated 
and the apps promise that we can indeed behold of ourselves through them. When this promise becomes plausible, however, desire becomes conflated with anxiety and that which we long for comes to haunt us.

\subsection{British Object Relations and Media Studies}

The British psychoanalytic object relations school mostly revolves around the psychoanalysts Melanie Klein, D. W. Winnicott, Ronald Fairbairn and others who developed Freud's ideas. Briefly put, object relations mark a departure from Freud's one-person psychology towards a more relational and intersubjective approach that aims to take account of the multitude of relations and attachments that make up our "inner worlds". In relation to the media, it is Winnicott's terms and concepts in particular that have been taken up by media scholars. His notions of the "transitional object" and "potential space" (Winnicott, 2002) have been adapted in fan studies (Hills, 2002, 2005, 2014; Sandvoss, 2005), for example, in order to explore fans' relationships with their objects of fandom that often span decades and are of biographical as well as sociocultural significance. Furthermore, Candida Yates and Caroline Bainbridge's Media and the Inner World research network (e.g. Bainbridge \& Yates, 2014) has been dedicated to interrogating the role of (object-relational) psychoanalysis in contemporary media cultures by bringing scholars, media practitioners and clinicians together.

Winnicott's concepts of the transitional object and potential space also take centre stage in Candida Yates and Iain MacRury's article "Framing the Mobile Phone: The Psychopathologies of an everyday Object". Reviewing the body of cultural research literature on the mobile phone as well as applications of the concept of "transitional object" in culture and media studies, Yates and MacRury work out how - and how far - the mobile phone can indeed be understood as "transitional" in Winnicott's sense. With the mobile blurring boundaries between "me" and "not-me", absence and presence, subject and object, work and free time, control and surveillance, they argue that it can be legitimately identified as a transitional object and understood as a way of expressing, reflecting on and enacting states and feelings linked to the unconscious and the potential space. However, this potentiating, transitional function can never be entirely taken for granted as regards our various attachment styles. Drawing on the work of Thomas Ogden (1992), the authors explicate both the healthy and pathological ways in which the potential of the mobile can become unfolded. 


\subsection{Trauma Theory and Media Studies}

Sigmund Freud defined trauma as "an experience which within a short period of time presents the mind with an increase of stimulus too powerful to be dealt with or worked off in the normal way [...]" (Freud, 1961: 275). Along this line, we can think of trauma as a rupture in the subject, as something so profoundly life changing and threatening to the subject's coherence and wellbeing that the ego blocks images, memories or thoughts touching upon that event from entering consciousness. While, throughout the past decades, the notion of trauma has been developed and modified in various ways (see e.g. Felman \& Laub, 1992; Caruth, 1995; Kaplan, 2005; Radstone, 2007; Leys, 2010; Meek, 2010; Pinchveski, 2012), the most recent development concerns work revolving around the idea of the "traumatic image" (Meek, 2010: 32). Specific events or images are either framed as traumatic by the media, or the media coverage itself is seen to have the potential to traumatise audiences. In his contribution, "Media Traumatization, Symbolic Wounds and Digital Culture", Allen Meek inquires into this idea in detail. Departing from Bettelheim's concept of the "symbolic wound" (1955), Meek explores the idea of collective trauma and how it manifests itself in contemporary digital culture. He traces the academic discussions of Geza Roheim's film Subincision (1937), which depicts subincision rites amongst an Aboriginal tribe, as well as subsequent research that drew on it. Meek argues that images that have traditionally been associated with trauma and, thus, with overwhelming, anxiety-provoking and paralysing effects, can now be observed being circulated online for various political purposes and with radically different psychosocial effects. Images such as the broadcasting of police violence on Facebook may be proactively captured by specific groups and used to challenge hegemonic power structures. Even ISIS videos of beheadings can be expected to have an identificatory appeal. Meek grounds his observations in Bruno Bettelheim's reading of Roheim's Subincision. In contrast to all later uses of the film in experimental stress and empathy tests, Bettelheim argued that the shocking, ritualistic wounds that the members of the tribe inflicted on each other should be appreciated for their participatory, self-transformative and collective dimensions of meaning. The idea of the symbolic wound that can be used for self-transformation, collective identification and group participation may, according to Meek, act as a corrective to the dominant idea of trauma as necessarily rendering a subject passive and as being inherently negative, stressful and disempowering. 


\subsection{Jungian and Post-Jungian Studies}

While C. G. Jung started out in close collaboration with Freud, changes in his thinking led to him breaking away from the founding father of psychoanalysis, with their fundamental disagreements revolving around the role of libido and sexuality in the individual subject. In his own approach to psychoanalysis, which he subsequently unfolded, Jung emphasised the existence of a collective unconscious made up of commonly held memories and ideas transmitted from generation to generation. The notion of the archetype as the basic form of those transmissions became central to Jung's work and it is not surprising that film scholars over the years have drawn on Jungian ideas in their works (Hauke \& Alister, 2000; Hockley, 2007; Singh, 2009, 2014; Hauke \& Hockley, 2011; Izod \& Dovalis, 2015). There are, however, few works on contemporary digital culture that make use of Jungian theory (Balick, 2014). A welcome exception is Greg Singh's article "YouTubers, Online Selves and the Performance Principle: Notes from a post-Jungian Perspective", which develops Jung's concept of "persona" in relation to popular YouTube vloggers. As Singh points out, Jung $(1953,1971)$ defined persona as "a psychological archetype of social adaptation" (p. 178) - something that can be understood as a fixed, routinised performance based on expectations of what is socially acceptable in a given context and society at large. While Jung stressed the danger of over-identifying with one's persona, Singh works out how such over-identification becomes inevitable in the context of Youtube and social media in general, where mechanisms of commodification and exploitation continuously encourage users to identify with their persona instead of the less defended parts of their subjectivities.

From a Jungian perspective, alienation in digital media thus approximates what Marcuse (1955) called the "performance principle". Singh makes this evident in his discussion of successful YouTube stars and their audiences: "If YouTubers themselves are conforming to the needs of the apparatus [i.e. the online platform, S.K. and J.J.] through content production and the performance of conventions associated with professional vlogging, YouTube end-users are also conforming to their own assigned roles as commodified objects." (p. 187). 


\subsection{Media Philosophy and Psychoanalysis}

Coinciding with Singh's work, Colin Campbell, in his article, "A Digital Death Drive? Hubris and Learning in Psychoanalysis and Cybernetics", also draws on Herbert Marcuse's writings for his confrontation of the digital. Campbell approaches digital media from a perspective that results from his interest in both Freudian psychoanalysis and Batesonian cybernetics. Arguing that the idea of the digital has become a fetish in Western culture, he relates Bateson's notion of "hubris" to Freud's conceptualisation of the death drive. From the perspective of this comparison, he holds that the term "digital" now widely stands for - and, indeed, camouflages - a process of abstraction, cutting-up and fragmentation and an emptying out of a lived experience. "[T]he digital fetish numbs us to the profound relation between body and machine, technology and nature" (p. 199). The moment of hubris lies in the act of mistaking digital representation as the whole of lived experience - an act that approximates the workings of the Freudian death drive in that it follows "a craving for stillness and order and the cessation of tensions" (p. 204). In opposition to this thanatotic tendency in contemporary culture, Campbell promotes a utopian approach to the understanding of our lifeworld that combines Bateson's theory of learning with Marcuse's conception of Eros. As Campbell writes, such an approach would involve "a profound analog-digital integration, a quantum leap forward in the capacity of language and consciousness to map social experience richly, without forgetting the traumatic cut digital language applies" (p. 211).

Campbell's argument points us in the direction of media philosophy as a field that has also put forth productive accounts of contemporary life in digital media in which psychoanalytic thinking is combined with questions of epistemology and the ontology of media technology. Mark B. Hansen (2000, 2004, 2006), for example, has drawn on Sigmund Freud and Didier Anzieu in his writings on technology and new media, in which the use of psychoanalysis goes beyond questions of subjectivity and is deployed to reconceptualise technology itself. Similar questions have been explored in Bernard Stiegler's work on pharmacology that has made use of Freud and Winnicott, amongst others.

Related to the media philosophical approaches above, Mike Featherstone's article on the "Chaosmic Spasm" combines Stiegler's concern (2013) for forms of care and carefulness along Winnicott's lines with Guattari's (1995) and Berardi's (2015) conceptualisations of "chaosmosis" and the "chaosmic spasm". 
All of these authors diagnose a hyper-acceleration of globalised and mediatised lifeworlds that is seen to result in a process of disorientation and de-subjectivisation. The individual subject is incapable of meaningfully situating itself in social, symbolic structures because of a symbolic order that has become commodified to a degree that reduces it to a carrier of quantitative value only. In the gradual intensification of this state, the notion of the spasm marks its climax as well a caesura, giving way to a utopian, hopeful moment of post-apocalyptic transformation and reparation.

\section{The Future of Psychoanalytic Media Research}

The notions of "transformation" and "reparation" give us our cues for the final part of this Introduction. On the basis of the above overview, we want to end here with a brief outlook on the future challenges for psychoanalytic explorations of media culture. Broadly, we identify three such challenges that may (indeed, should) also be read as potentials for development.

The first of these challenges concerns a shift in theories and methodologies that revolve around so-called "big data". Emerging disciplines such as digital sociology, digital humanities, software studies, science and technology studies, and computational social sciences are symptomatic of a general drive towards quantification in academia: terms such as "digital methods" often signify quantitative methods for providing data analytics of large datasets that have been extracted from social media with the help of automated software. This "digital positivism" (Fuchs, 2017: 4) - an empiricist fetishisation of data, algorithms and structural processes - comes at the expense of a focus on subjectivity, micro processes, forms of interaction, engagement and agency that threatens any theoretical exploration of notions of the subject or the media user more specifically. While we do not wish to dispute the manifold roles that data now play in our lives, responses to it must continue to take account of both big and small data, i.e. quantitative and qualitative frameworks. This is especially pertinent in the light of the possible changes in the nature of the unconscious itself with regard to the subject's situatedness within media in contemporary culture. If media are increasingly inhabiting all aspects of everyday life, the emerging question is how can we reconceptualise the conscious and unconscious relationalities between people and their evolving media technologies? We maintain that psychoanalysis is one of the disciplines that lends itself to researching such questions. 
Thus, rather than merely arguing for a reconceptualisation of the social in the light of mediatisation processes, as Andreas Hepp and Nick Couldry (2016) have recently done, we argue for a reconceptualisation of the psychosocial dimensions that engulf, entangle and surround societies, individuals, structures and media spheres today. In this respect, turning our critique here into a positive call for future research, psychoanalytically-oriented researchers should be encouraged not to shy away from this drive towards the quantitative, but, on the contrary, to actively engage with it, interpret the data as well as the methods by which these data are gathered and processed and point towards the manifold ways in which our conceptions of subjectivity, relationality and sociality have bearings on the findings derived from the quantitative.

The second challenge revolves around psychoanalytic theory itself and its often contested status within academia. Frequently, we find New Materialist, Deleuzian and Foucauldian approaches (amongst others) to be conceived in rather stereotypical opposition to psychoanalysis - an opposition that does justice to neither field. Large parts of contemporary affect theories, for example, have established themselves in opposition to psychoanalysis and its perceived over-individualising viewpoint. While this may have been a rather hasty and reductive attempt at establishing a new terrain - affect studies - the question remains as to whether there is not significant potential within the various psychoanalytic theories that have the power to critique, contest, modify and, ultimately, further the above approaches. Offering the briefest of examples for this, our point is corroborated forcefully by Jacques Derrida (2001: 87), when he suggests in view of Foucault's critique of psychoanalysis that we might find "already in Freud, to say nothing of those who followed, discussed, transformed, and displaced him, the very resources of the objection levelled against [...] the father of psychoanalysis". Again, turning this point of critique into a call for research, while there are many laudable impulses to be found in the present issue, further work is needed that criss-crosses theoretical fields and negotiates between psychoanalysis and other theoretical approaches - not in order to create false harmonies, but to determine in detail where the differences and contradictions between the fields lie.

Thirdly, and most importantly, what is needed is more hands-on, empirical research from a psychoanalytic and/or psychosocial perspective. Generally, while psychoanalytic theories can offer profound insights into media-cultural 
processes from the micro to the macro level, we still have to improve the ways in which we bring these theories and their insights to the reality we seek to understand. In this respect, a substantial part of psychoanalytic media scholarship risks overwhelming its audience with a dense theoretical discourse that remains on a decisively abstract level. If psychoanalysis is to secure a place within media research, it needs to open itself up to other paradigms and, fundamentally, to empirical research. Questions around methodology and the extent to which psychoanalysis can be a method in social and cultural research are important in this respect (Johanssen, 2016a, b; Krüger, 2016). We believe that this issue of $C M$ both addresses and illuminates the challenges and potential of psychoanalysis for digital media research today. 


\section{References}

Adorno, T. W. (1954). How to Look at Television. The Quarterly of Film, Radio and Television, 8(3): 213-235.

Adorno, T. W. (1975). Culture Industry Reconsidered. New German Critique, (6): $12-19$.

Ahmed, S. (2014). The Cultural Politics of Emotion. Second Edition. Edinburgh: Edinburgh University Press.

Bainbridge, C. \& Yates, C (eds.) (2014). Media and the Inner World: Psychocultural Approaches to Emotion, Media and Popular Culture. Basingstoke: Palgrave Macmillan.

Balick, A. (2014) The Psychodynamics of Social Networking: Connected-up Instantaneous Culture and the Self. London: Karnac.

Baxmann, I., Beyes, T. \& Pias, C. (eds.) (2014). Soziale Medien - Neue Massen. Zürich and Berlin: Diaphanes.

Berardi, F. (2015). And: Phenomenology of the End. New York: Semiotext(e).

Bessi, A. \& Ferrara, E. (2016). Social Bots distort the 2016 US Presidential Election Online Discussion. First Monday, 21(11). URL: http://firstmonday.org/ojs/index.php/fm/article/view/7090.

Bettelheim, B. (1955). Symbolic Wounds: Puberty Rites and the Envious Male. London: Thames and Hudson.

boyd, d. (2014). It's Complicated: The Social Lives of Networked Teens. New Haven: Yale University Press.

boyd, d. \& Crawford, K. (2012). Critical Questions for Big Data: Provocations for a Cultural, Technological, and Scholarly Phenomenon. Information, Communication \& Society, 15(5): 662-679.

Bröckling, U. (2016). The Entrepreneurial Self. Fabricating a New Type of Subject (translated by Steven Black). London: SAGE.

Brown, S. D. \& Lunt, P. (2002). A Genealogy of the Social Identity Tradition: Deleuze and Guattari and Social Psychology. British Journal of Social Psychology, 41(1): 1-23.

Bruns, A. (2008). Blogs, Wikipedia, Second Life, and beyond: From Production to Produsage New York: Peter Lang. 
Bucher, T. (2012). Want to be on the Top? Algorithmic Power and the Threat of Invisibility on Facebook. New Media \& Society, 14(7), 1164-1180.

Burston, J., Dyer-Witheford, N. \& Hearn, A. (2010). Digital Labour: Workers, Authors, Citizens. Ephemera: Theory and Politics in Organization (Special issue), 10(3/4): 214-221.

Butler, J. (1990). Gender Trouble. Feminism and the Subversion of Identity. London: Routledge.

Carpentier, N. (2011). Media and Participation: A Site of Ideological-democratic Struggle. Bristol: Intellect.

Caruth, C. (1995). Trauma: Explorations in Memory. Baltimore: John Hopkins University Press.

Copjec, J. (1989) The Orthopsychic Subject: Film Theory and the Reception of Lacan. October, 49: 53-72.

Couldry, N. \& Hepp, A. (2016). The Mediated Construction of Reality. London: Wiley.

Couldry, N. (2000). Inside Culture: Re-imagining the Method of Cultural Studies. London: SAGE.

Cowie, E. (1990). Fantasia. In Adams, P. \& Cowie, E. (eds.), The Woman in Question (pp. 149-196). London: Verso.

Dahlgren, P. (2013). Tracking the Civic Subject in the Media Landscape. Versions of the Democratic Ideal. Television \& New Media, 14(1): 71-88.

De Lauretis, T. (1984). Alice doesn't: Feminism, Semiotics, Cinema. Bloomington: Indiana University Press.

Dean, J. (2009). Democracy and Other Neoliberal Fantasies: Communicative Capitalism and Left Politics. Durham: Duke University Press.

Dean, J. (2010). Blog Theory: Feedback and Capture in the Circuits of Drive. Cambridge: Polity.

Dean, T. (2000). Beyond Sexuality. Chicago: University of Chicago Press.

Derrida, J. (2001). Michel Foucault (1926-84): “To do Justice to Freud”. In Derrida, J., The Work of Mourning (eds.: Brault, P.-A. \& Naas, M., pp. 77-90). Chicago: University of Chicago Press.

Doane, M. A. (1987). The Desire to Desire: The Woman's Film of the 1940s. Washington: Georgetown University Press. 
Edelman, L. (2004). No Future: Queer Theory and the Death Drive. Durham: Duke University Press.

Elliott, A. \& Urry, J. (2010). Mobile Lives. London: Routledge.

Felman, S. \& Laub, D. (1992). Testimony: Crises of Witnessing in Literature, Psychoanalysis, and History. New York: Taylor \& Francis.

Fisher, E. (2012). How Less Alienation Creates More Exploitation? Audience Labour on Social Network Sites. tripleC: Communication, Capitalism \& Critique. Open Access Journal for a Global Sustainable Information Society, 10(2): 171-183.

Flisfeder, M. \& Willis, L. (eds.) (2014). Zizek and Media Studies: A Reader. Basingstoke: Palgrave Macmillan.

Flisfeder, M. (2015). The Entrepreneurial Subject and the Objectivization of the Self in Social Media. South Atlantic Quarterly, 114(3): 553-570.

Freud, A. (1936/1984). Das Ich und die Abwehrmechanismen. Frankfurt a. M.: Fischer.

Freud, S. (1915). Repression. The Standard Edition of the Complete Psychological Works of Sigmund Freud, Volume XIV (1914-1916): On the History of the Psycho-Analytic Movement, Papers on Metapsychology and Other Works. London: The Hogarth Press and the Institute of Psycho-Analysis.

Freud, S. (1961). Fixation to Traumas - the Unconscious. The Standard Edition of the complete psychological Works of Sigmund Freud. Volume XVI. Introductory Lectures on Psycho-analysis (Part III). London: The Hogarth Press and the Institute of Psycho-Analysis.

Freud, S. (1950/1962). Aus den Anfängen der Psychoanalyse. Frankfurt a. M.: Fischer.

Freud, S. (1978). Five Lectures on Psycho-analysis. The Standard Edition of the Complete Psychological Works of Sigmund Freud. Volume XI. Five Lectures on Psycho-analysis, Leonardo da Vinci and other Works. London: The Hogarth Press and the Institute of Psycho-Analysis.

Freud, S. (1981). Civilization and its Discontents. The Standard Edition of the Complete Psychological Works of Sigmund Freud. Volume XXI. The Future of an Illusion, Civilization and its Discontents and other Works. London: The Hogarth Press and the Institute of Psycho-analysis. 
Fromm, E. (1941/1994). Escape from Freedom. New York: Henry Holt Publishers.

Frosh, S. (2002). Key Concepts in Psychoanalysis. London: The British Library.

Frosh, S. (2012). A Brief Introduction to Psychoanalytic Theory. Basingstoke: Palgrave Macmillan.

Fuchs, C. (2014). Digital Labour and Karl Marx. Routledge.

Fuchs, C. (2017). From Digital Positivism and Administrative Big Data Analytics towards Critical Digital and Social Media Research! European Journal of Communication, online first, http://journals.sagepub.com/doi/ abs/10.1177/0267323116682804.

Giglietto, F., Iannelli, L., Rossi, L. \& Valeriani, A. (2016). Fakes, News and the Election: A New Taxonomy for the Study of Misleading Information within the Hybrid Media System. SSRN Conference Proceedings. URL: https:// papers.ssrn.com/sol3/papers.cfm?abstract_id=2878774.

Gillespie, T. (2014). The Relevance of Algorithms. In Gillespie, T., Boczkowski, P. \& Foot, K. (eds.), Media Technologies. Essays on Communication, Materiality and Society (pp. 167-194). Cambridge, MA: MIT Press.

Grossberg, L. (1987). The In-difference of Television. Screen, 28(2): 28-46.

Guattari, F. (1995). Chaosmosis: An Ethico-Aesthetic Paradigm. Sydney: Power Press.

Habermas, J. (1972). Knowledge and Human Interest. Boston: Beacon Press.

Hall, S. (1980) Encoding/decoding. In Hall, S., Hobson, D., Lowe, A. \& Wil-

lis, P. (eds.), Culture, Media, Language: Working Papers in Cultural Studies, 1972-79 (pp. 117-127). London: Hyman.

Halpern, O. (2014). Beautiful Data. A History of Vision and Reason since 1945. Durham and London: Duke University Press.

Hansen, M. B. N. (2000). Embodying Technesis. Technology beyond Writing. Ann Arbor, MI: University of Michigan Press.

Hansen, M. B. N. (2004). New Philosophy for New Media. Cambridge, MA: MIT press.

Hansen, M. B. N. (2006). Bodies in Code. Interfaces with Digital Media. London: Routledge. 
Hauke, C. \& Alister, I. (eds.) (2000). Jung and Film: Post-Jungian Takes on the Moving Image. London: Routledge.

Hauke, C. \& Hockley, L. (eds.) (2011). Jung and Film II-The Return: Further Post-Jungian Takes on the Moving Image. London: Routledge.

Hills, M. (2002). Fan Cultures. London: Routledge.

Hills, M. (2005). Patterns of Surprise. The 'Aleatory Object' in Psychoanalytic Ethnography and Cyclical Fandom. American Behavioral Scientist, 48(7): 801-821.

Hills, M. (2014). Playing and Pathology: Considering Social Media as "Secondary Transitional Objects".' In Bainbridge, C. \& Yates, C (eds.), Media and the inner World: Psycho-cultural Approaches to Emotion, Media and Popular Culture (pp. 185-200). Basingstoke: Palgrave Macmillan.

Hinshelwood, R. D. (1991). A Dictionary of Kleinian Thought. Second Edition. London: Free Association Books.

Hockley, L. (2007). Frames of Mind: A Post-Jungian Look at Cinema, Television and Technology. Bristol: Intellect.

Hogan, B. (2013). Pseudonyms and the Rise of the Real-Name Web. In Hartley, J., Burgess, J. \& Bruns, A. (eds.), A Companion to New Media Dynamics (pp. 290-307). Chichester: Blackwell.

Hollway, W. \& Jefferson, T. (2000). Doing Qualitative Research Differently. Free Association, Narrative and the Interview Method. London: Sage.

Horkheimer, M. \& Adorno, T. W. (1972). Dialectic of Enlightenment. Stanford: Stanford University Press.

Izod, J. \& Dovalis, J. (2015). Cinema as Therapy: Grief and Transformational Film. London: Routledge.

Jenkins, H. (2006). Convergence Culture: Where Old and New Media Collide. New York: NYU Press.

Johanssen, J. (2016a). Did We Fail? (Counter-) transference in a Qualitative Media Research Interview. Interactions: Studies in Communication \& Culture, 7(1): 99-111.

Johanssen, J. (2016b). Media Research and Psychoanalysis: A Suggestion. International Communication Gazette, 78(7): 688-693. 
Jung, C. G. (1953). Two Essays on Analytical Psychology. New York: Pantheon Books.

Jung, C. G. (1971). Psychological Types. London: Routledge.

Kaplan, A. M. \& Haenlein, M. (2010). Users of the World, Unite! The Challenges and Opportunities of Social Media. Business Horizons, 53(1): 59-68.

Kaplan, E. A. (2005). Trauma Culture: The Politics of Terror and Loss in Media and Literature. New Brunswick, NJ: Rutgers University Press.

Karppi, T. (2015). Happy Accidents: Facebook and the Value of Affect. In: Hillis, K., Paasonen, S., \& Petit, M. (2015). Networked Affect. Cambridge, MA: MIT Press, 221-234.

König, H.-D. (2006). Rechtsextremismus in Fernsehdokumentationen. Psychoanalytische Rekonstruktion ihrer Wirkungsweise. Gießen: Psychosozial.

Kris, E. (1952). Psychoanalytic Explorations in Art. New York: International University Press.

Krüger, S. (2016). Understanding Affective Labor Online: A Depth-hermeneutic Reading of the My 22nd of July Webpage. Ephemera, 16(4), 185-208.

Krüger, S. \& Johanssen, J. (2014). Alienation and Digital Labour-A DepthHermeneutic Inquiry into Online Commodification and the Unconscious. tripleC: Communication, Capitalism \& Critique. Open Access Journal for a Global Sustainable Information Society, 12(2): 632-647.

Krzych, S. (2010). Phatic Touch, or The Instance of the Gadget in the Unconscious. Paragraph, 33(3): 376-391.

Lacan, J. (1977). Ecrits: A Selection. New York: Norton.

Lacan, J. (2007). The Other Side of Psychoanalysis. New York: Norton.

Laplanche, J. \& Pontalis, J.-B. (1973). The Language of Psycho-analysis. New York: Norton

Leys, R. (2010). Trauma: A Genealogy. Chicago: University of Chicago Press.

Lister, M., Dovey, J., Giddins, S., Grant, I. \& Kelly, K. (2009). New Media. A Critical Introduction (Second Edition). New York: Routledge.

Löchel, E. (2002). "Es könnte etwas dabei herauskommen”. Psychologische Aspekte textbasierter "virtueller" Realität und Beziehungsmuster jugendlicher Chatter. Psychosozial, 25(88): 61-72. 
Lorenzer, A. (1970a). Sprachzerstörung und Rekonstruktion. Frankfurt a. M.: Suhrkamp.

Lorenzer, A. (1970b). Kritik des psychoanalytischen Symbolbegriffs. Frankfurt a. M.: Suhrkamp.

Lorenzer, A. (1986). Tiefenhermeneutische Kulturanalyse. In Lorenzer, A. et al. (eds.), Kulturanalysen (pp. 11-98). Frankfurt a. M.: Fischer.

Lupton, D. (2016). The Quantified Self. London: Wiley.

Mager, A. (2012). Algorithmic Ideology: How Capitalist Society Shapes Search Engines. Information, Communication \& Society, 15(5): 769-787.

Marcuse, H. (1955). Eros and Civilization: A Philosophical Inquiry into Freud. Boston: Beacon Press.

Marcuse, H. (1964/1991). One-Dimensional Man: Studies in Ideology of Advanced Industrial Society. Second Edition. London: Routledge.

Marwick, A. E. \& boyd, d. (2011). I Tweet Honestly, I Tweet Passionately: Twitter Users, Context Collapse, and the Imagined Audience. New Media \& Society, 13(1): 114-133.

Marwick, A. E. \& boyd, d. (2014). Networked Privacy: How Teenagers Negotiate Context in Social Media. New Media \& Society, 16(7): 1051-1067.

Meek, A. (2010). Trauma and Media: Theories, Histories, and Images. London: Routledge.

Mitscherlich, A. \& Mitscherlich, M. (1967/2007). Die Unfähigkeit zu Trauern. Munich: Piper.

Moffitt, B. (2016). The Global Rise of Populism: Performance, Political Style, and Representation. Stanford: Stanford University Press.

Morley, D. (1986). Family Television: Cultural Power and domestic Leisure. London: Routledge.

Mulvey, L. (1975). Visual Pleasure and Narrative Cinema. Screen, 16(3): 6-18. Neville, L. (2015). Male Gays in the Female Gaze: Women who Watch m/m Pornography. Porn Studies, 2(2-3): 192-207.

Ogden, T. H. (1992). The Matrix of the Mind; Object Relations and the Psychoanalytic Dialogue. London: Karnac Books.

Parker, I. (2010). Psychosocial Studies: Lacanian Discourse Analysis Negotiating Interview Text. Psychoanalysis, Culture and Society, 15(2): 156-172. 
Phillips, W. (2015). This Is Why We Can't Have Nice Things: Mapping the Relationship between Online Trolling and Mainstream Culture. Massachusetts: MIT Press.

Pinchevski, A. (2012). The Audiovisual Unconscious: Media and Trauma in the Video Archive for Holocaust testimonies. Critical Inquiry, 39(1): 142-166.

Radstone, S. (2007). Trauma Theory: Contexts, Politics, Ethics. Paragraph, 30(1): 9-29.

Ryberg, I. (2015). Carnal Fantasizing: Embodied Spectatorship of Queer, Feminist and Lesbian Pornography. Porn Studies, 2(2-3): 161-173.

Saco, D. (2002). Cybering Democracy. Public Space and the Internet. Minneapolis: University of Minnesota Press.

Saito, K. (2011). Desire in Subtext: Gender, Fandom, and Women's Male-Male Homoerotic Parodies in Contemporary Japan. Mechademia, 6: 171-191.

Sandvoss, C. (2005). Fans: The Mirror of Consumption. London: Polity.

Silverman, K. (1992). Male Subjectivity at the Margins. London: Routledge.

Singh, G. (2009). Film after Jung: Post-Jungian Approaches to Film Theory. London: Routledge.

Singh, G. (2014). Recognition and the Image of Mastery as Themes in Black Mirror (Ch4, 2011-present): An Eco-Jungian Approach to "Always-on" Culture'. International Journal of Jungian Studies, 6(2): 120-132.

Stiegler, B. (2013). What Makes Life Worth Living: On Pharmacology. Cambridge: Polity Press.

Stutzman, F., Gross, R. \& Acquisti, A. (2013.) Silent Listeners: The Evolution of Privacy and Disclosure on Facebook. Journal of Privacy and Confidentiality, 4(2): 7-41.

Suler, J. (2004). The Online Disinhibition Effect. Cyberpsychology \& Behavior, 7(3): 321-326.

Terranova, T. (2000). Free Labor: Producing Culture for the Digital Economy. Social Text, 18(2): 33-58.

Turkle, S. (2012). Alone Together: Why We Expect More from Technology and Less from Each Other. New York: Basic Books.

Turkle, S. (2015). Reclaiming Conversation: The Power of Talk in a Digital Age. London: Penguin. 
Turow, J. (2011). The Daily You. How the New Advertising Industry is Defining Your Identity and Your Worth. New Haven \& London: Yale University Press. Van Dijck, J. (2013). The Culture of Connectivity: A Critical History of Social Media. New York: Oxford University Press.

Varghese, R. (2016). Sex/work. Porn Studies, 3(2): 191-194.

Watson, E. (2009). Queering Psychoanalysis/Psychoanalysing Queer. Annual Review of Critical Psychology, 7: 114-139.

Westen, D. (1999). The Scientific Status of Unconscious Processes: Is Freud Really Dead?. Journal of the American Psychoanalytic Association, 47(4), 1061-1106.

Wilson, M. (2010). The Possibilities of Networked Sociality. In Hunsinger, J, Klastrup, L. \& Allen, M. (eds.), International Handbook of Internet Research (pp. 493-505). Heidelberg: Springer.

Winnicott, D. W. (2002). Playing and Reality. London: Routledge.

Zajc, M. (2015). Social Media, Prosumption, and Dispositives: New Mechanisms of the Construction of Subjectivity. Journal of Consumer Culture, 15(1): 28-47.

Zaretsky, E. (2015). From Psychoanalysis to Cybernetics: The Case of Her. American Imago, 72(2): 197-209.

Žižek, S. (1997). Cyberspace, or, the Unbearable Closure of Being. In Žižek, S., The Plague of Fantasies (pp. 161-213). London and New York: Verso.

\section{Acknowledgements}

Jacob Johanssen and Steffen Krüger would like to thank the reviewers who worked on this issue for their help, as well as the CM editors, particularly Jelena Kleut, for the friendly cooperation and enthusiastic engagement.

Steffen Krüger is funded by the FRIPRO programme of the Norwegian Research Council (NFR). 
Thinking (with) the Unconscious in Media

Steffen Krüger

and Communication Studies

Jacob Johanssen 